\title{
Determining the ecotoxicological mode of action of toxic chemicals in meiobenthic marine organisms: stage-specific short tests with Tisbe battagliai
}

\author{
Carlos Barata ${ }^{1,2, *}$, Donald J. Baird ${ }^{1}$, Matias Medina1, Amaya Albalat ${ }^{1}$, \\ Amadeu M. V. M. Soares ${ }^{2}$ \\ ${ }^{1}$ Institute of Aquaculture, University of Stirling, Stirling FK9 4LA, Scotland, UK \\ ${ }^{2}$ Departamento de Biologia, Universidade de Aveiro, Campus de Santiago, 3810-193 Aveiro, Portugal
}

\begin{abstract}
A short-term Tisbe battagliai toxicity test design was used to assess the potential ecological effects of pollutants in coastal marine communities. By exposing nauplii and reproductive females over 4 and $6 \mathrm{~d}$, respectively, to 3 toxic substances (fluoranthene, cypermethin and deltamethrin), the bioassay was seen to successfully measure survival effects on egg, nauplii and adults and sublethal effects on food acquisition and clutch size. Predictive consequences of toxic exposure at population level was estimated in terms of reproductive success, by integrating effects on adult survival and reproductive performance over the studied exposure period. Fluoranthene exposure reduced feeding rate and clutch size at concentrations below those affecting survival and population responses. For cypermethrin, survival, sublethal and reproductive success concentration effects were of a similar magnitude. For deltamethrin adult and nauplii survival, clutch size and reproductive success were equally affected at concentrations which were lower than those affecting feeding and egg survival. Responses to contaminated algae showed a different pattern, with toxicant effects only on nauplii survival and reproductive success, and under exposure to pyrethroid insecticides. Thus, differences in the dominant ecotoxicological modes of action, in terms of the balance between survival and sublethal responses with potential effects at the population level, could be successfully assessed using this short-term bioassay. These results have important implications for risk assessment in estuarine and coastal waters because with relatively short-term, and thus cost-effective tests, the functional relationship between effects on survival, feeding and reproduction rates and concentration can be determined.
\end{abstract}

KEY WORDS: Life-history effects · Fluoranthene $\cdot$ Cypermethrin $\cdot$ Deltamethrin $\cdot$ Sublethal tests Resale or republication not permitted without written consent of the publisher

\section{INTRODUCTION}

Coastal areas are among the most productive of marine environments and also serve as the recipients for high loads of human-derived pollutants (Abel \& Axiak 1991, Kenish 1992). Toxic chemicals enter coastal areas in association with water and sediment, and are, for the most part, accumulated in the sedi-

${ }^{*}$ Present address: Department of Environmental Chemistry, IIQAB-CSIC, Jordi Girona 18, Barcelona 08034, Spain.

E-mail: cbmqam@cid.es ment section. Thus, benthic fauna are likely to be chronically exposed to marine pollutants (Chandler et al. 1994, Lotufo 1997, 1998). Hence, a full evaluation of ecological effects of chemical contaminants on coastal environments should consider toxic effects on demographic responses of representative benthic species (Hutchinson \& Williams 1989, Bechmann 1994, Hutchinson et al. 1994, 1999, Chandler \& Green 2001). A limitation to this approach has been the cost and length of time required to generate demographic toxicity data. As toxic inputs in coastal areas vary considerably over time, frequent cost-effective measurements of toxicity 
are essential. Therefore, tests estimating demographic responses to toxic events in coastal areas should be of short duration (Hutchinson \& Williams 1989).

Population effects are often inferred from observations made at the level of the individual. To make predictions concerning an individual's contribution to population responses, age-specific survival, fecundity and timing of reproduction must be measured and combined to estimate demographic parameters (Calow et al. 1997, Forbes et al. 2001). Exposure to a toxic substance may affect population responses by reducing juvenile and adult survival. Alternatively, toxic exposure may also affect demographic responses, impairing resource acquisition and thus reducing offspring production and/or increasing developmental rates (Di Pinto et al. 1993, Green \& Chandler 1996, Lotufo 1997 , Barata \& Baird 2000). Discrimination between survival (lethal) and sublethal (i.e. resource acquisition) effects of toxic substances is important in ecotoxicology because the resulting combination of these 2 effects, which will likely differ among toxic substances, may have differing consequences at the community and ecosystem level. For example, both lethal and sublethal effects on zooplankton could have long-term effects on secondary production (Moore \& Folk 1993). However, toxic substances with effects on resource acquisition could also affect phytoplankton communities by their influence on grazing, thus increasing the risk of algal blooms (Jak et al. 1996).

Although it is possible to obtain information on lethal and sublethal toxic effects from existing short-term marine bioassays, no single test method encompasses the full complement of potential life-history effects required to predict population consequences of exposure to a pollutant. Lethal tests provide information on adult or juvenile survivorship, but no information on production rates are assessed (ASTM 1988). Tests based on sublethal responses such as reproductive output and juvenile developmental rates (Hutchinson \& Williams 1989, ASTM 1990, Williams 1992, Hutchinson et al. 1994) may allow collection of information on lethal and sublethal effects, but this information is incomplete and may be confounded, for example by failing to distinguish between effects on embryonic or juvenile survivorship during development versus energy allocation to eggs (e.g. Baird et al. 1991).

Toxic substances can have multiple toxicological modes of action. It is therefore crucial to focus our toxicological investigations to study the dominant ecotoxicological (sensu Barata \& Baird 2000) mode of action, based on the concentration at which various toxicological effects become potentially operative at the population or ecosystem level (Calow et al. 1997, Forbes et al. 2001). By developing test designs which allow us to quantify and separate lethal and sublethal effects, it should be possible to group chemicals by the effects that they exert on individuals in terms of their population or ecosystem consequences. This could be simply achieved from existing life-cycle tests conducted with sibling species of the meiobenthic copepod Tisbe (Bechmann 1994, 1999, Hutchinson et al. 1999). For example, by measuring a few additional variables such as feeding rate. Furthermore, by exposing adult females and nauplii in separate tests it should also be possible to shorten the duration of these tests to as little time as it takes for the production of a couple of broods.

The study of Barata \& Baird (2000) demonstrated that sublethal (growth and reproduction) responses to toxic chemicals of Daphnia females exposed over a single reproductive event ( 3 to $4 \mathrm{~d}$ ) were similar to those obtained in long-term studies $(21 \mathrm{~d})$. These results were related to the fact that food acquisition is usually affected immediately upon exposure to toxic chemicals, and resources allocated to growth and reproduction are determined from the resources acquired between reproductive events (Nogueira 1996). Medina et al. (2002) studying acute effects of cypermethrin in nauplii and adult stages of Acartia tonsa, showed that exposure periods longer than $3 \mathrm{~d}$ should be selected to assess lethal effects (i.e. $\mathrm{LC}_{50}$ ). Thus, by exposing copepod nauplii over $4 \mathrm{~d}$ and copepod adult females over a few reproductive events it is possible to measured lethal and sublethal effects. Thus, the aim of our study was to investigate whether by making a few simple adjustments to the existing Tisbe life-cycle protocol to include measurements of feeding rates and egg mortality, and limiting exposure periods to $4 \mathrm{~d}$ for nauplii and the production of 2 clutches for adults (i.e. $6 \mathrm{~d}$ at $20^{\circ} \mathrm{C}$ under optimal food conditions; Williams \& Jones 1999), it is possible to derive a test design of similar ecological relevance, yet which is less labour intensive and costly than existing demographic procedures (e.g. Bechmann 1994, 1999).

The marine bioassay organism Tisbe battagliai Volkmann-Rocco was chosen as it occurs commonly in shallow, coastal waters throughout Europe and North America, and is an important food source for fish and macroinvertebrates (Williams \& Jones 1999). T. battagliai is also sensitive to a variety of environmental contaminants and is currently used in assessment of water quality in estuarine and coastal waters (Hutchinson \& Williams 1989, Williams 1992, Hutchinson et al. 1994, Thomas et al. 1999). Furthermore, as an opportunistic scavenger and common representative of the meiobenthos (Lopez 1982, Villano \& Warwick 1995), T. battagliai can be exposed to pollutants through a variety of routes associated with sediment, food particles and water.

The ecotoxicological modes of action of different pollutants were determined by studying lethal effects 
on egg, naupliar and adult survivorship, and sublethal effects on food acquisition and hence on clutch size of adult females. Effects on individuals were translated into population responses by determining the reproductive success, which was expressed as the female offspring produced by an adult female during the test. Although the reproductive success does not account for toxicant effects on developmental rates and juvenile survival, it integrates effects on egg and adult survival as well as fecundity across reproductive events, and hence can be considered a partial estimate of the net reproductive rate, $R_{0}$ (Stearns 1992). The proposed design was tested using 3 organic chemicals and 2 exposure routes. In particular, meiobenthic copepods were exposed to aqueous and foodassociated fluoranthene, cypermethrin and deltamethrin. Fluoranthene is a polycyclic aromatic hydrocarbon (PAH) that is a common contaminant in many coastal systems, usually associated with discharge of petroleum and atmospheric depositions of combustion by-products (Kenish 1992, Lotufo \& Fleeger 1997, Lotufo 1998). Insecticide pyrethroids such as cypermethrin and deltamethrin occur in marine coastal areas usually associated with agricultural runoff (Chandler et al. 1994). Both pyrethroids can also enter the marine coastal environment from chemotherapeutic sea lice control products (Burridge et al. 2000, Roth 2000). The high hydrophobicity of PAH and pyrethroid insecticides favours their partitioning to sediment and suspended particles such as algae (Kenish 1992, Chandler et al. 1994, Zhou et al. 1995, Zhou \& Rowland 1997, Lotufo 1998). Thus, it is not surprising to find that sediment-associated fluoranthene and pyrethroid insecticides strongly affect feeding and hence impair reproduction of meiobenthic copepods (Clark et al. 1989, Chandler 1990, Chandler et al. 1994, Lotufo 1998). Nevertheless, meiobenthic copepods such as Tisbe can feed continuously by grazing on algae (Villano \& Warwick 1995). Thus, algae-associated fluoranthene, cypermethrin and deltamethrin may also affect population responses of meiobenthic copepods.

\section{MATERIALS AND METHODS}

Test organisms. Adults and new-born (nauplii) copepods used in this study originated from continuous cultures successfully maintained at Brixham Environmental Laboratory (Hutchinson \& Williams 1989). Tisbe battagliai were cultured in $0.2 \mu \mathrm{m}$ filtered natural seawater (30 psu), collected from Saint Andrews, Scotland, and maintained at $20 \pm 1{ }^{\circ} \mathrm{C}$. Copepods were fed every $2 \mathrm{~d}$ with a mixed 1:1 diet of microalgae Isochrysis galbana and Rhinomonas reticulata at a concentra- tion of $1 \times 10^{5}$ cells ml $^{-1}$, equivalent to $1.9 \mu \mathrm{gC} \mathrm{ml}^{-1}$ (after Kleppel \& Burkart 1995). Cultures were maintained at $20^{\circ} \mathrm{C}$ under a photoperiod of 16:8 h light:dark cycle and changed every $2 \mathrm{~d}$ to maintain oxygen and food levels. The procedures for culturing the 2 algal food species has been described previously (Williams \& Jones 1994).

At $20^{\circ} \mathrm{C}$ and under optimal food conditions, an average new-born nauplius of Tisbe battagliai requires 10 to $12 \mathrm{~d}$ to reach adulthood (Williams \& Jones 1999). After a single copulation, sexually mature females can produce 6 to 7 broods (egg sacs) throughout their life (1 every 3 to 4 d) (Hutchinson \& Williams 1989, Williams \& Jones 1999). Furthermore, adult females do not moult after reaching sexual maturity, and thus all energy resources acquired by adult females are potentially available for maintenance and reproduction. Thus, by exposing reproductive females over 2 reproductive events (i.e. 6 d) sublethal toxic effects on reproduction can be assessed. Furthermore, egg viability can also be estimated by comparing clutch size with offspring production after a $6 \mathrm{~d}$ exposure.

Experimental design. Four experiments were performed. In the first 3, Tisbe battagliai were exposed to aqueous concentrations of fluoranthene, cypermethrin and deltamethrin in the presence of food. In the fourth experiment, $T$. battagliai were exposed to algae preloaded with each of the 3 toxicants in clean seawater.

Exposure to aqueous concentrations of the 3 studied toxicants. Toxicity tests were conducted in 2 different life-stages of Tisbe battagliai, namely adult females carrying egg sacs and nauplii. Experiments with adults lasted $6 \mathrm{~d}$ and were initiated with first reproductive females (just before they release their first egg sacs). Females were held in groups of 10 in $50 \mathrm{ml}$ borosilicate containers filled with $40 \mathrm{ml}$ of the appropriate test solution whilst male copepods were excluded (as a single copulation enabled females to produce fertile eggs throughout their reproductive period, Hutchinson et al. 1994). Experimental treatments consisted of 4 replicates of a fed and starved control (no toxic substance added), and 4 to 6 test concentrations for fluoranthene, cypermethrin and deltamethrin. As experiments were started with ovigerous females derived from laboratory cultures, the inclusion of starved controls allowed us to judge whether observed life-history patterns were influenced by the previous culture regime. In all treatments, $T$. battagliai were transferred to newly prepared solutions every other day. Except for the starved control treatments, $T$. battagliai were fed every other day with a mixture of Isochrysis galbana and Rhinomonas reticulata $\left(1.9 \mu \mathrm{g} \mathrm{C} \mathrm{ml}^{-1}\right)$. Copepod mortality and the presence of offspring in each test chamber was monitored daily over $6 \mathrm{~d}$ using a binocular stereomicroscope. After $6 \mathrm{~d}$ 
of exposure, surviving females were collected to determine clutch size and egg viability. To determine clutch size, egg sacs were gently removed from freshly killed females and their eggs counted using a binocular microscope. Females were killed by overexposing them to $\mathrm{CO}_{2}$-saturated seawater. To estimate egg survival, from each treatment, 8 females carrying egg sacs ( 2 replicate $^{-1}$ ) were randomly chosen and held in individual $5 \mathrm{ml}$ cultures until the release of their brood. Egg survival was then expressed as the ratio between the number of offspring produced versus the average clutch of females of similar age, replicate and treatment. In addition, groups of 20 copepod nauplii were exposed to the 3 studied toxic chemicals over $4 \mathrm{~d}$. Experimental treatments consisted of 4 replicates of a fed control and 4 to 6 test concentrations of fluoranthene, cypermethrin and deltamethrin. Nauplii mortality was recorded daily. The remaining experimental conditions were identical to those described for adult females.

Feeding trials were conducted between the first and second test renewal ( 2 to $4 \mathrm{~d}$ of exposure) following the same experimental protocol described for the reproduction experiments. For each treatment, 2 blank replicates filled with the same culture medium but with no Tisbe battagliai were included to ensure that algae did not grow during the feeding trials. The mean initial algal cell concentration of the experimental vessels at the start of the experiment (time $=t_{0}$ ) was determined from three $40 \mathrm{ml}$ samples obtained from the treatment medium before it was distributed into all the experimental vessels. After $48 \mathrm{~h}$, the final cell concentration $\left(t_{48}\right)$ of the 6 replicates of each treatment ( 2 blanks, 4 treatment replicates) were assessed using the whole test volume $(40 \mathrm{ml})$. All algal samples were immediately centrifuged $(5000 \times g$ for $25 \mathrm{~min}$ ), resuspended in $1 \mathrm{ml}$, preserved in Lugol's solution and stored at $4{ }^{\circ} \mathrm{C}$. Algae concentrations were determined using a haemocytometer (haemocytometer BS 748 improved Neubauer 1/400 $\mathrm{mm}^{2}$ ). Feeding was then determined using the cell-difference method following Allen et al. (1995).

Exposure to preamended algae. Toxicity tests were only conducted with adult females carrying egg sacs. Adult females were exposed to algae preloaded with each of the 3 chemicals in clean seawater. Algae cells were preloaded by adding $0.7,3.5$ and $50 \mu \mathrm{g} \mathrm{l}^{-1}$ of deltamethrin, cypermethrin and fluoranthene, respectively, to a 11 sample of algae with a cell density of $1 \times 10^{5}$ cells ml $^{-1}$ and left for $24 \mathrm{~h}$ in darkness. The algae were then centrifuged $(5000 \times g$ for $25 \mathrm{~min})$ and after discarding the supernatant, the algae cells were resuspended in $1 \mathrm{l}$ of uncontaminated seawater to provide the stock suspension for each toxicant. Experimental treatments consisted of 4 replicates of both a fed and starved control (no toxic substance added), and 3 toxicant concentrations, 1 per each toxic chemical studied. Copepod mortality and the presence of offspring in each test chamber were monitored every other day over $6 \mathrm{~d}$. This allowed us to indirectly assess nauplii survival between sampling dates $(48 \mathrm{~h})$. The remaining experimental conditions were identical to those described under exposures to both water and food.

Water chemistry. Saturated aqueous stock solutions of deltamethrin (Pestanal, RdH Laborchemikalien, 99.8\% purity), cypermethrin ( $40 \%$ cis- $58 \%$ trans, SUPELCO, $99.5 \%$ purity) and fluoranthene (Aldrich, 98\% purity) were prepared following the method described by Barata \& Baird (2000): $1 \mathrm{ml}$ of $0.1 \mathrm{mg} \mathrm{ml}^{-1}$ of deltamethrin and cypermethrin and $1 \mathrm{ml}$ of $1 \mathrm{mg} \mathrm{ml}^{-1}$ of fluoranthene solutions in acetone were allowed to completely evaporate in a 21 borosilicate glass container. Then the container was filled with 11 of $0.2 \mu \mathrm{m}$ filtered seawater and mixed in an orbital incubator for $2 \mathrm{~d}$. Prior to the preparation of test concentrations, stock solutions were filtered through a glass microfibre filter $(0.2 \mu \mathrm{m})$ to obtain only the maximum soluble fraction of the chemical. In seawater, this amount corresponds to $1.5,7.0$ and $100 \mathrm{\mu g} \mathrm{l}^{-1}$ of deltamethrin, cypermethrin and fluoranthene, respectively (Verschueren 1983, Hayes \& Laws 1991). Nominal test concentrations ( $\mu \mathrm{g}$ $\left.\mathrm{I}^{-1}\right)$ of deltamethrin $(0,0.005,0.01,0.025,0.05,0.1,0.2$, $0.75)$, cypermethin $(0,0.025,0.05,0.1,0.2,0.4,3.5)$ and fluoranthene $(0,10,25,50,100)$ were prepared by adding appropriate aliquots of the stock solution to filtered seawater. Stocks were kept in darkness at $4^{\circ} \mathrm{C}$ during the experiments.

For the 3 chemicals studied, duplicate water samples of freshly prepared $\left(t_{0}\right)$ and old test $\left(t_{48}\right)$ solutions were collected from experimental vessels at the beginning and end of tests. Due to the low solubility in seawater of deltamethrin $\left(<1.5 \mu \mathrm{g} \mathrm{l}^{-1}\right)$ and cypermethrin $\left(<7 \mu \mathrm{g} \mathrm{l}^{-1}\right)$, actual concentrations were only determined from $400 \mathrm{ml}$ water samples of the filtered stock solutions used in each experiment. Fluoranthene analysis was restricted to $50 \mathrm{ml}$ water samples at 3 concentrations: 25, 50 and $100 \mu \mathrm{g} \mathrm{l}^{-1}$. Prior to extraction, water samples were pretreated with propan-2-ol and acidified with nitric acid. Test solutions of the 3 chemicals were extracted from water and preconcentrated in a solid-phase, Bond Elut C18 extraction column (Varian, Phenomenex). Deltamethrin and cypermethrin were eluted from the solid-phase cartridges with a mixture of acetonitrile:toluene of 3:1 and $3: 1.5$, respectively, whereas fluoranthene was eluted with a mixture of propan-2-ol:glacial acetic acid:toluene:petroleum ether of 0.9:0.1:2:7. The obtained solutions were then evaporated using a rotary vacuum evaporator (Genelac SF 60, Corning) and the 
residue resuspended in $2 \mathrm{ml}$ of mobile phase. Actual concentrations of the 3 chemicals were determined by HPLC using the method of Carvalho et al. (1995). For the 3 chemicals, $100 \mu \mathrm{l}$ of the final sample extract was injected onto a SUPELCOSIL ${ }^{\mathrm{TM}} 59142$ LC-ABZ $5 \mu \mathrm{m}$ pore size $2.5 \mathrm{~cm} \times 4.6 \mathrm{~mm}$ column (SUPELCO). A mobile liquid phase of acetonitrile:water (75:25 and 80:20 for pyrethroid insecticides and fluoranthene, respectively) was used. A flow rate of $1.0 \mathrm{ml} \mathrm{min}{ }^{-1}$ and wavelengths of 210 and $242 \mathrm{~nm}$ were set to analyse pyrethroid insecticides and fluoranthene, respectively. The multivariate calibration method proposed by Martinez Galera et al. (1996) was used to integrate cis- and trans-cypermethrin isomers. Chromatographic data analysis was carried out using a PC1000 v2.5 software (Thermo separation Products). Retention times for deltamethrin, cypermethrin and fluoranthene were 9.6, 8.5 and $8 \mathrm{~min}$, respectively. Recovery of pyrethroid insecticides and fluoranthene from water samples was determined from duplicated standard solutions of known concentration, which were extracted and eluted at the same time as test solutions. Mean recoveries $\pm 1 \mathrm{SD}(\%)$ of deltamethrin, cypermethrin and fluoranthene from water samples were $85 \pm 4,87 \pm 5.2$ and $98 \pm 3 \%$, respectively $(\mathrm{n}=4)$. Dissolved oxygen, $\mathrm{pH}$ and salinity were also measured at the beginning and end of tests.

Statistical analysis. Nauplii survival responses after $4 \mathrm{~d}$ and adult and egg survival data after $6 \mathrm{~d}$ were used to estimate lethal concentration effects $\left(\mathrm{LC}_{10-50}\right)$. Although the experimental methods employed here allowed estimation of lethal concentration effects (i.e. $\mathrm{LC}_{50}$ ) over different exposure periods (i.e. $24,48,72$, $96,120,148 \mathrm{~h})$, in a previous study we showed that cypermethrin- $\mathrm{LC}_{50}$ obtained for adult and nauplii copepod stages decreased with increasing exposure time (Medina et al. 2002). For this reason, in the present study only survival responses and lethal concentration effects obtained at the end of the exposure period are depicted. To increase the accuracy of lethal concentration measurements $\left(\mathrm{LC}_{10-50}\right)$, adult and nauplii survival data from the 4 replicates were pooled (Barata \& Baird 2000). Egg survival was expressed as the proportion of nauplii produced per averaged egg sac size after $6 \mathrm{~d}$ of exposure. For each replicate $\times$ treatment combination, clutch size was determined as the averaged number of eggs produced per surviving female after $6 \mathrm{~d}$ of exposure. Thus, clutch size values included females with and without egg sacs. The reproductive success was determined from the total number of female offspring produced per day per living female $\left(m_{x}\right)$ and the age-specific survival $\left(l_{x}\right)$ over $4 \mathrm{~d}$ of exposure (Stearns 1992). As experiments were started with ovigerous females derived from laboratory cultures, production of first brood of offspring was judged to have been influenced by the previous culture regime. Consequently, analysis of total number of offspring produced excluded values from the first $2 \mathrm{~d}$. Assuming a sex ratio of 1:1 in nauplii (Bechmann 1994), reproductive success can be expressed as:

$$
\text { Reproductive success }=\sum_{x=3}^{6} m_{x} l_{x}
$$

where: $l_{x}=$ number of living females on Day $x /$ number of females at start of the experiment; $m_{X}=$ (number of nauplii produced on Day $x / 2$ )/number of living females on Day $x$.

Life-history trait responses including survival, clutch size, feeding rates and reproductive success across actual fluoranthene, cypermethrin and deltamethrin dissolved chemical concentrations ( $\log _{\mathrm{e}}$ transformed) were used to estimate lethal $\left(\mathrm{LC}_{10-50}\right)$, sublethal and reproductive success concentration effects $\left(E_{10-50}\right)$. Effect concentration values (EC) were determined from a regression-based approach performed on raw rather than transformed data. This allowed us to consider information about the real sample distribution of each concentration and controls (Barata \& Baird 2000). The non-linear allosteric decay regression model was selected to fit the data obtained as it can describe threshold biological responses (Allen et al. 1995, Barata \& Baird 2000, Barata et al. 2000). Confidence intervals (95\%) associated to $\mathrm{LC}_{10-50}$ and $\mathrm{EC}_{10-50}$ were determined following the procedure of Barata et al. (2000). Prior to analysis, toxicant concentrations were $\log _{\mathrm{e}}$ transformed. Model accuracy was assessed by using adjusted coefficient of determination, $\mathrm{r}^{2}$, and by analysing residual distribution (Zar 1996). Significance of the entire regression and regression coefficients were determined by $F$ - and $t$-tests, respectively (Zar 1996). Whenever inspection of residuals evidenced non-homogeneity of variance, the estimates were corrected using the weight-least square method, where the weight was proportional to the reciprocal of the variance.

Data obtained in the fourth experiment among exposure treatments and controls, and in all experiments between control and starving control treatments were compared by ANOVA procedures. Adult and nauplii survival data were analysed using chisquare and F-exact test, whereas egg survival, feeding rates, clutch size and reproductive success were analysed using 1-way ANOVA followed by Dunnett's tests. This allowed the identification of statistically significant differences $(p<0.05)$ between control and treatment groups. In all traits, raw data were tested for normality ( $p>0.05$; Kolmogorov-Smirnov tests). In the few cases where variances were heteroscedastic $\left(p<0.05\right.$, Bartlett's test) data were $\log _{\mathrm{e}}$ transformed prior to analysis. 


\section{RESULTS}

\section{Chemical analysis}

Actual fluoranthene concentrations of freshly prepared solutions were $30 \%$ higher than expected, but old solutions differed by $30 \%$ from freshly prepared solutions ( $\mathrm{p}<0.05$; Student's $t$-tests, Table 1$)$. Thus, actual concentrations of fluoranthene in test solutions were based on the interpolated midpoint value between initial and final concentrations. Actual concentrations of cypermethrin and deltamethrin in freshly prepared stocks were 66 and $39 \%$ lower than expected, and decreased again by 35 and $44 \%$, respectively, after $48 \mathrm{~h}$ (Table 1). Therefore, actual concentrations of cypermethrin and deltamethrin in test solutions were based on dilutions of the measured concentrations of stock solutions which were determined as the interpolate midpoint value between initial and final concentrations.

In all cases, oxygen levels in freshly prepared and old test solutions were within $90 \%$ of saturation levels. Mean $\mathrm{pH}$ and salinity values were 8.1 and $30 \mathrm{psu}$, respectively, and differences between initial and final values never exceeded 0.2 and 2 units, respectively.

\section{Life-history responses of Tisbe battagliai}

In all 4 experiments (Figs. 1 to 4 ), females deprived of food for $6 \mathrm{~d}$ produced smaller clutches than those fed on uncontaminated alga ( $\mathrm{p}<0.05$; Student's $t$-tests). Furthermore, except in the bioassay performed with deltamethrin, starvation also affected female survivorship ( $\mathrm{p}<0.05, F$-exact tests). As a consequence, starvation significantly affected reproductive success ( $p<0.05$, Student's $t$-tests).

Table 1. Nominal versus measured concentrations $\left(\mu \mathrm{g} \mathrm{l}^{-1}\right)$ of fluoranthene, cypermethrin and deltamethrin in freshly prepared $\left(t_{0}\right)$ and old test solutions $\left(t_{48}\right)$. Duplicate samples taken at the beginning and end of the tests have been pooled $(n=4)$.

Standard deviations are shown in parentheses

\begin{tabular}{|lrc|}
\hline \multirow{2}{*}{ Nominal } & \multicolumn{2}{c|}{ Effective concentration } \\
& Mean $t_{0}$ & Mean $t_{48}$ \\
\hline Fluoranthene & & \\
25 & $38.56(2.87)$ & $22.74(2.76)$ \\
50 & $74.32(3.51)$ & $47.35(5.41)$ \\
100 & $140.37(5.84)$ & $93.65(9.70)$ \\
Cypermethrin & & \\
7 & $3.14(0.26)$ & $2.04(0.20)$ \\
Deltamethrin & & \\
1.5 & $0.91(0.07)$ & $0.51(0.09)$ \\
\hline
\end{tabular}

\section{Exposure to aqueous concentrations of fluoranthene, cypermethrin and deltamethrin}

Survival, sublethal (i.e. clutch size, feeding rates) and reproductive success responses to fluoranthene, cypermethrin and deltamethrin followed the allosteric decay model, in which no or low response at low concentrations occurs, followed by an accelerating negative response as concentrations increase (Figs. 1, 2 \& 3). In all cases, the residuals of the regressions obtained were normally distributed $(\mathrm{p}>0.05$; KolmogorovSmirnov tests) and the coefficients of determination were greater than 0.5 (Table 2). For fluoranthene, low concentration effects for feeding and clutch size responses were lower than those reported for lethal $\left(\mathrm{LC}_{10}\right)$ and reproductive success responses $\left(\mathrm{EC}_{10}\right.$; Table 2). However, high sublethal, lethal and reproductive success effects $\left(\mathrm{LC}_{50}, \mathrm{EC}_{50}\right)$ were of similar magnitude (Table 2). This apparent contradiction
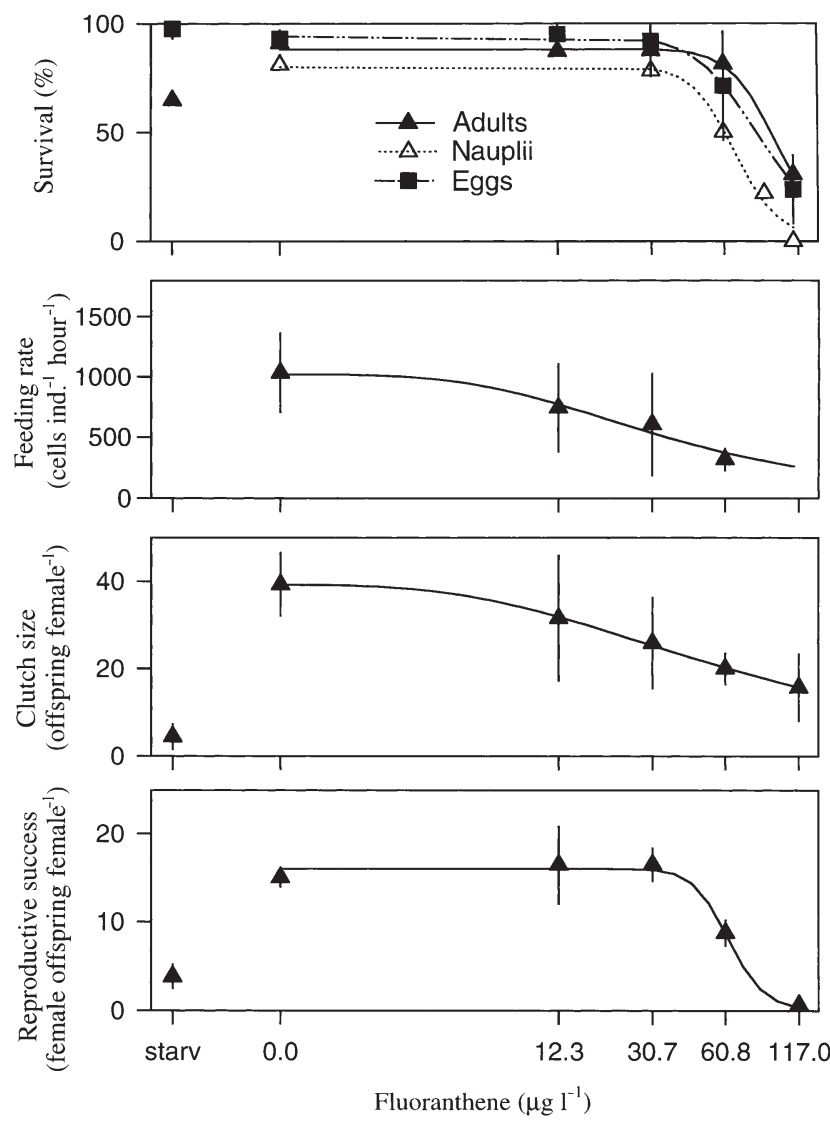

Fig. 1. Survival and sublethal responses (mean $\pm 1 \mathrm{SD}$ ) including egg, nauplii and adult survival, feeding rate, clutch size and reproductive success as a function of aqueous fluoranthene concentrations. Data have been fitted to an allosteric decay model. Responses of starving females (starv) are also depicted. Exposure periods were $4 \mathrm{~d}$ for nauplii and $6 \mathrm{~d}$ for adults and eggs 
arises from the fact that allosteric curves for clutch size and feeding response were less steep than those obtained for survival and reproductive success responses (Fig. 1). Survival, clutch size, feeding rates and reproductive success responses were equally sensitive to cypermethrin (Fig. 2). Consequently, lethal, sublethal and reproductive success concentration effects of cypermethrin were of a similar magnitude (Table 2). For deltamethrin adult and nauplii survival, clutch size and reproductive success were equally affected at concentrations which were lower than those affecting feeding and egg survival (Fig. 3, Table 2).

\section{Exposure to preamended algae}

Exposure to algae contaminated with fluoranthene, cypermethrin and deltamethrin only affected reproductive success responses $\left(F_{3,12}=15.2, \mathrm{p}<0.05\right.$; Fig. 4$)$.
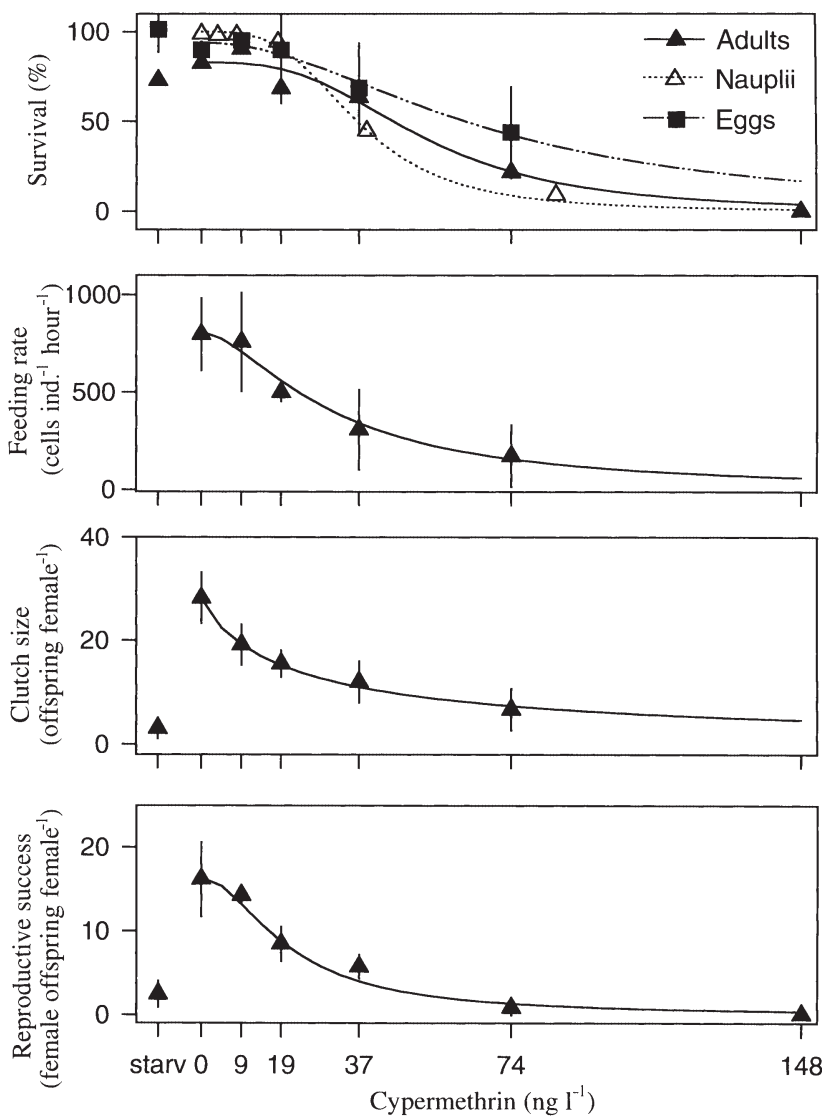

Fig. 2. Survival and sublethal responses (mean $\pm 1 \mathrm{SD}$ ) including egg, nauplii and adult survival, feeding rate, clutch size and reproductive success as a function of aqueous cypermethrin concentrations. Data have been fitted to an allosteric decay model. Responses of starving females (starv) are also depicted. Exposure periods were $4 \mathrm{~d}$ for nauplii and $6 \mathrm{~d}$ for adults and eggs
In particular, females exposed to algae preloaded with cypermethrin and deltamethrin and those feeding on uncontaminated algae produced clutches of similar size and most of their eggs were viable. However, between sampling dates ( 2 d) only $50 \%$ of the nauplii produced by females feeding on algae contaminated with pyrethroids survived. As a consequence, reproductive success responses were significantly affected under exposure to cypermethrin and deltamethrin.

\section{DISCUSSION}

The results reported here showed that by exposing nauplii and adult females of Tisbe battagliai over 4 and $6 \mathrm{~d}$, respectively, to 3 toxicants (fluoranthene, cypermethrin and deltamethrin), it was possible to successfully measure lethal effects on egg, naupliar and adult stages, and non-lethal effects on food acquisition and
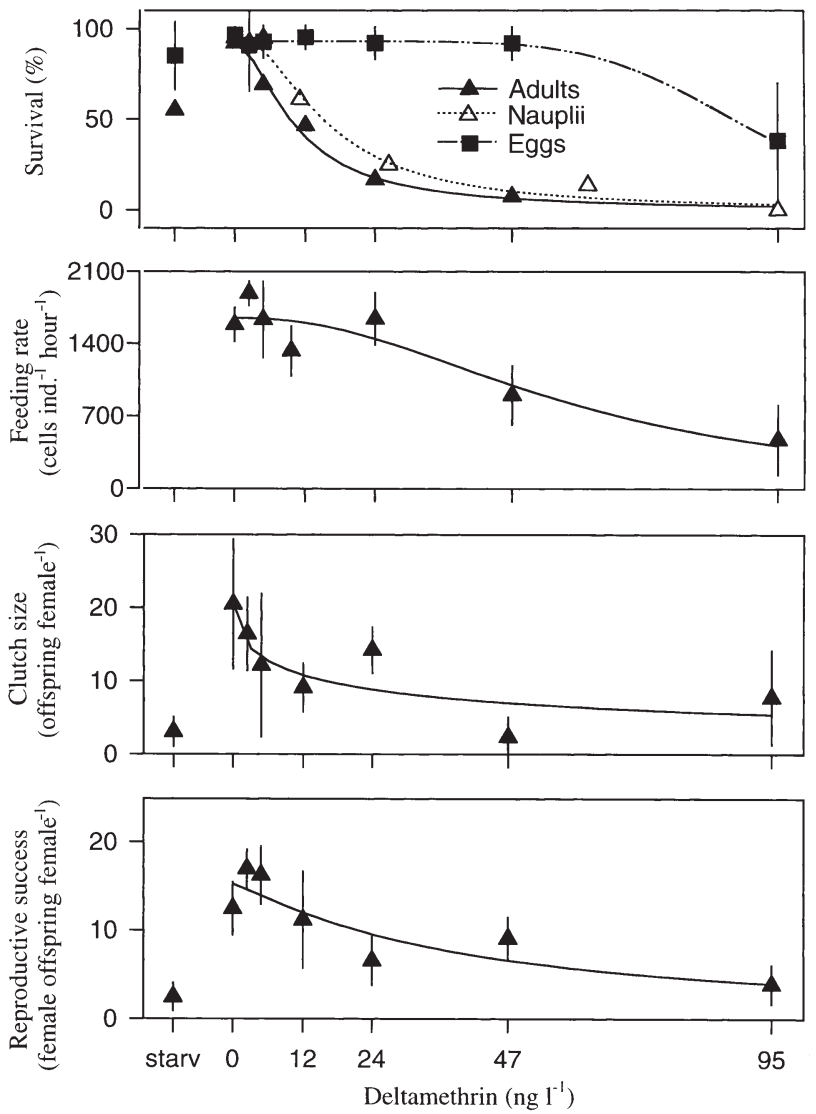

Fig. 3. Survival and sublethal responses (mean $\pm 1 \mathrm{SD}$ ) including egg, nauplii and adult survival, feeding rate, clutch size and reproductive success as a function of aqueous deltamethrin concentrations. Data have been fitted to an allosteric decay model. Responses of starving females (starv) are also depicted. Exposure periods were $4 \mathrm{~d}$ for nauplii and $6 \mathrm{~d}$ for adults and eggs 

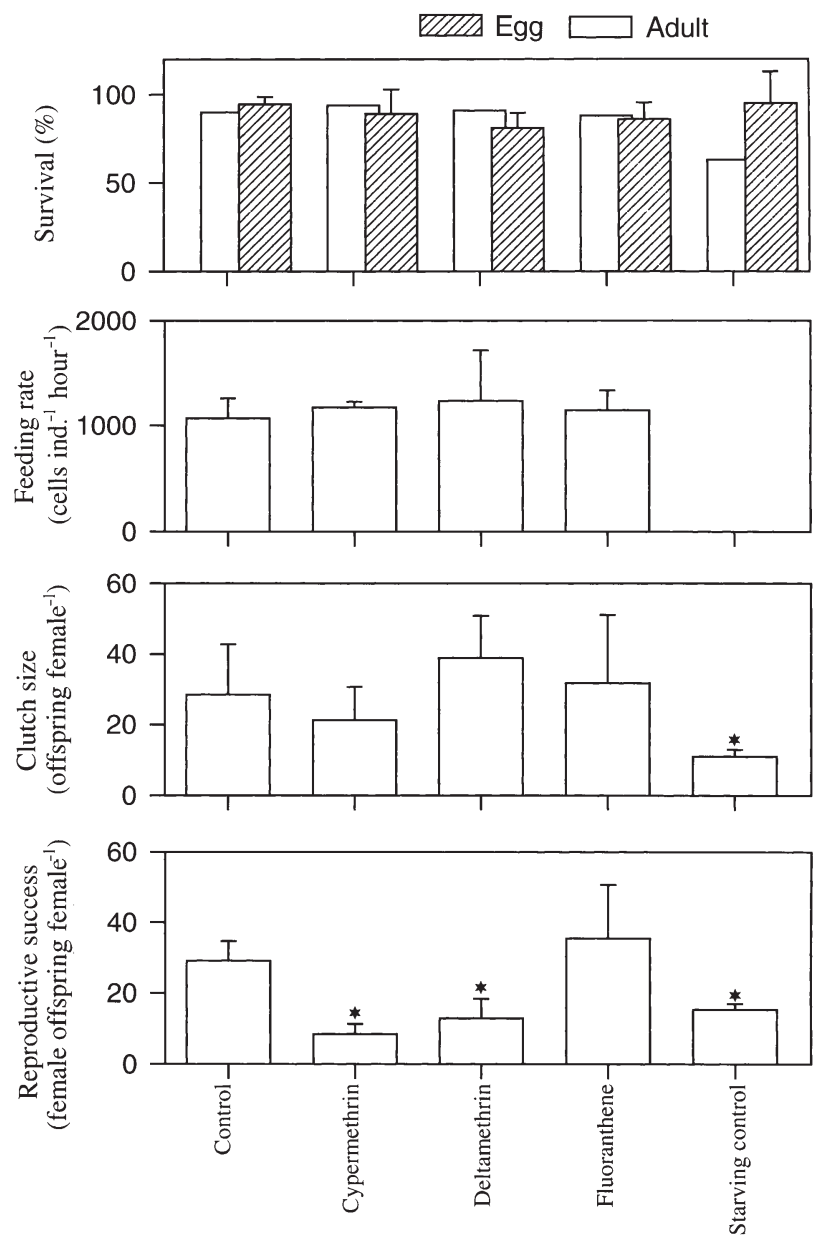

Fig. 4. Survival and sublethal responses (mean $\pm 1 \mathrm{SD}$ ) including egg and adult survival, feeding rate, clutch size and reproductive success to contaminated algae spiked with 60 , 1.3 and $0.35 \mathrm{\mu g} \mathrm{l}^{-1}$ of fluoranthene, cypermethrin and deltamethrin, respectively. Responses of females fed non-contaminated algae (controls) and starving controls are also depicted. The exposure period was $6 \mathrm{~d}$. ${ }^{*}$ Significant difference $(\mathrm{p}<0.05)$ from control mean

reproduction rates. Fluoranthene exposure reduced feeding rates and clutch size at concentrations below those affecting survival responses. For cypermethrin, sublethal and survival concentration effects had a similar magnitude. For deltamethrin, adult and nauplii survival and clutch size were equally affected at concentrations which were lower than those affecting feeding and egg survival. Responses to algae contaminated with fluoranthene, cypermethrin and deltamethrin showed a different pattern, with toxicant effects only occurring on nauplii survival and under exposure to pyrethroid insecticides. Thus, differences in the dominant ecotoxicological modes of action, in terms of the balance between survival and sublethal responses with potential effects at the population level, can be successfully assessed using this short-term bioassay.
Once the functional relationship has been quantified, extrapolation from pollutant effects on individuals to populations can be achieved by assessing the relative sensitivity of population parameters to changes in lifehistory traits (Calow et al. 1997, Forbes et al. 2001) or, alternatively, determining toxicant effects on population responses (Forbes \& Calow 1999). In the present study, sensitivities of the population parameter, namely reproductive success, to the studied chemicals did not always agree with those observed for individual traits. Pyrethroid insecticide concentration effects on reproductive success were similar to those observed for sublethal (clutch size) and survival responses. However, for

Table 2. Toxic effects on selected life-history traits of Tisbe battagliai nauplii, eggs and adult females carrying egg sacs after 4 (nauplii) and $6 \mathrm{~d}$ (eggs and adults) of exposure. $\mathrm{LC}_{10-50}$ and $\mathrm{EC}_{10-50}$ values were determined assuming an allosteric decay non-linear model. $95 \% \mathrm{CI}$ for $\mathrm{LC}_{10-50}$ and $\mathrm{EC}_{10-50}$ are shown in parentheses. Values are reported in $\mu \mathrm{g} \mathrm{l}^{-1}$ for fluoranthene and in $\mathrm{ng} \mathrm{l}^{-1}$ for cypermethrin and deltamethrin; $\mathrm{r}^{2}$ : coefficient of determination; $\mathrm{n}$ : sample size; ${ }^{*} \mathrm{p}<0.05$

\begin{tabular}{|c|c|c|c|c|}
\hline $\begin{array}{l}\text { Survival } \\
\text { effects }\end{array}$ & $\mathrm{LC}_{10}$ & $\mathrm{LC}_{50}$ & $\mathrm{n}$ & $\mathrm{r}^{2}$ \\
\hline \multicolumn{5}{|l|}{ Fluoranthene } \\
\hline Nauplii & $44.4(26.4-74.2)$ & $68.3(53.8-83.7)$ & 5 & $0.98^{*}$ \\
\hline Adults & $63.3(47.4-83.7)$ & $101.1(90.5-113.0)$ & 5 & $0.99^{*}$ \\
\hline Eggs & 46.9 (31.4-69.8) & $86.2(69.4-106.8)$ & 20 & $0.80^{*}$ \\
\hline \multicolumn{5}{|l|}{ Cypermethrin } \\
\hline Nauplii & 19.4 (13.7-25.0) & $37.3(33.4-41.2)$ & 6 & $0.99^{*}$ \\
\hline Adults & $26.8(3.2-51.1)$ & $52.0(29.1-75.4)$ & 6 & $0.96^{*}$ \\
\hline Eggs & $23.4(5.0-51.3)$ & $67.1(36.4-99.2)$ & 19 & $0.55^{*}$ \\
\hline \multicolumn{5}{|l|}{ Deltamethrin } \\
\hline Nauplii & $4.9(0.6-9.4)$ & $15.1(8.8-21.5)$ & 6 & $0.96^{*}$ \\
\hline Adults & $4.7(2.1-7.3)$ & $10.6(7.2-14.0)$ & 6 & $0.99^{*}$ \\
\hline Eggs & $64.1(22.4-107.6)$ & $88.7(71.9-106.3)$ & 27 & $0.63^{*}$ \\
\hline $\begin{array}{l}\text { Sublethal } \\
\text { effects }\end{array}$ & $\mathrm{EC}_{10}$ & $\mathrm{EC}_{50}$ & $\mathrm{n}$ & $\mathrm{r}^{2}$ \\
\hline \multicolumn{5}{|l|}{ Fluoranthene } \\
\hline Feeding rate & $7.8(1.6-43.7)$ & $34.0(9.0-121.9)$ & 15 & $0.51^{*}$ \\
\hline Clutch size & $9.2(1.1-46.9)$ & $66.9(21.9-200.9)$ & 20 & $0.54^{*}$ \\
\hline \multicolumn{5}{|l|}{ Cypermethrin } \\
\hline Feeding rate & $14.1(2.7-25.6)$ & $27.8(13.4-42.4)$ & 20 & $0.68^{*}$ \\
\hline Clutch size & $10.4(3.8-17.1)$ & $23.2(12.9-33.5)$ & 19 & $0.84^{*}$ \\
\hline \multicolumn{5}{|l|}{ Deltamethrin } \\
\hline Feeding rate & $28.1(12.1-43.9)$ & $58.1(41.0-75.6)$ & 27 & $0.70^{*}$ \\
\hline Clutch size & $8.7(0.8-17.0)$ & $13.8(10.1-38.3)$ & 27 & $0.65^{*}$ \\
\hline $\begin{array}{l}\text { Reproductive } \\
\text { success }\end{array}$ & $\mathrm{EC}_{10}$ & $\mathrm{EC}_{50}$ & $\mathrm{n}$ & $\mathrm{r}^{2}$ \\
\hline Fluoranthene & $44.1(27.5-71.9)$ & $63.4(56.6-71.1)$ & 20 & $0.89^{*}$ \\
\hline Cypermethrin & $9.3(4.5-14.1)$ & $22.2(15.9-28.4)$ & 24 & $0.89^{*}$ \\
\hline Deltamethrin & $16.1(2.7-29.7)$ & $37.8(11.7-64.7)$ & 28 & $0.60^{*}$ \\
\hline
\end{tabular}


fluoranthene, reproductive success and survival responses were affected at higher concentrations than sublethal responses. These results support the statement of Forbes \& Calow (1999) that there is no consistent pattern in terms of which individual level traits are more or less sensitive to toxic exposure than population traits. Indeed, Forbes \& Calow (1999) reported that in 33 out of 99 cases, population parameters were less sensitive than 1 or more individual level traits. This means that single tests based on survival, sublethal or population responses do not necessarily yield a complete picture of ecological effects of toxic chemicals. For example, in the present study, survival or population responses were unable to predict potential long-term effects of fluoranthene on phytoplankton communities due to effects on grazing. According to Jak et al. (1996) many toxic chemicals can cause eutrophication phenomena by inhibiting zooplankton grazing rates. In addition, survival and sublethal responses of adults were also unable to predict toxic effects of algae-associated pyrethroids due to effects on nauplii survival. Therefore, we have shown that this new test design can be used to quantify and separate multiple ecotoxicological models of action as measured through combined effects on individual life-history traits.

To recommend the use of this short-term. rapid bioassay as an alternative to existing lethal and reproduction tests performed with marine invertebrates, it would be necessary to compare the sensitivity of lifehistory responses obtained in the present bioassay with those reported in previous studies. Furthermore, as experiments with adults were started with ovigerous females derived from laboratory cultures, it was also necessary to judge whether observed life-history patterns were influenced by the previous culture regime. In all 4 tests performed, averaged adult survival, clutch size and reproductive success values of starving females were 48,80 and $74 \%$ lower, respectively, than those observed in control females. This means that the exposure period chosen $(6 \mathrm{~d})$ was long enough to minimise the influence of the previous culture regime.

Life-history response patterns of Tisbe battagliai exposed to fluoranthene in seawater agree with reported studies performed in meiobethic copepods and marine amphipods. Predicted concentration effects of fluoranthene in seawater for survival responses of different life-stages were similar to those observed for larvae of marine amphipoda species (i.e. $4 \mathrm{~d} \mathrm{LC}_{50}=$ 36 to $100 \mu \mathrm{g} \mathrm{l}^{-1}$ from Boese et al. 1997). Furthermore, observed life-stage and life-history patterns to fluoranthene such as a relatively greater sensitivity of eggs and nauplii than adults, and strong sublethal effects on feeding responses were also observed in long-term sediment bioassays conducted in meiobenthic cope- pods. Lotufo $(1997,1998)$ after exposing 2 meiobenthic copepod species to sediment-associated fluoranthene over 10 and $14 \mathrm{~d}$, respectively, found that sublethal effects on feeding and impairments of embryonic development occurred at lower concentrations than those causing adult mortality. Lotufo \& Fleeger (1997) studying toxic effects of sediment-associated phenanthrene on different life-stages of meiobenthic copepods also reported higher sensitivities for naupliar stages.

In the present study, adults and nauplii only showed marginal differences in sensitivity to deltamethrin and cypermethrin. More specifically, lethality thresholds (95\% confidence intervals, $\mathrm{CI}$, for $\mathrm{LC}_{10}$ ) for adults and nauplii varied from 3 to $51 \mathrm{ng} \mathrm{l}^{-1}$ for cypermethrin and from 0.6 to $9 \mathrm{ng} \mathrm{l}^{-1}$ for deltamethrin. Studies conducted with estuarine crustaceans and meiobenthic copepods have also reported similar sensitivities of juvenile and adult stages to pyrethroid insecticides (Chandler 1990, Cripe 1994). Toxicities to sensitive life-stages of other crustaceans such as amphipods, crayfish, shrimp and lobster have been reported from 4 to $200 \mathrm{ng} \mathrm{l}^{-1}$ for cypermethrin and $1.4 \mathrm{ng} \mathrm{l}^{-1}$ for deltamethrin (Clark et al. 1989, Day 1989, Cripe 1994, Burridge et al. 2000). Therefore, in the present bioassay, observed life-stage sensitivities of Tisbe battagliai to pyrethroids were of similar magnitude to those obtained for other crustaceans.

Few studies have reported sublethal or long-term toxic effects of pyrethroids on aquatic crustacea. Lifetime exposure of Daphnia populations to fenvalerate resulted in a decrease in clutch size at $5 \mathrm{ng} \mathrm{l}^{-1}$ (Day \& Kaushik 1987). Chandler (1990) studying sensitivities of 2 meiobenthic copepods to sediment-bound fenvalerate residues reported sublethal effects for clutch size at $25 \mu \mathrm{g} \mathrm{l}^{-1}$. In the present study, predicted low concentration effects $\left(\mathrm{EC}_{10}\right)$ for clutch size of cypermethrin and deltamethrin in seawater were 10.4 and $9.7 \mathrm{ng} \mathrm{l}^{-1}$, respectively. Thus, observed sublethal sensitivities of Tisbe battagliai to the studied pyrethroids were of similar magnitude of those obtained in Daphnia and much greater than those reported in sediment bioassays. Chandler (1990) also observed that negative effects of pyrethroid insecticides on the reproduction of meiobenthic copepods were associated with a decrease in clutch size and egg viability. In the present study, we also reported that pyrethroid insecticides impaired egg viability. Thus, observed pyrethroid effects on reproduction also agree with previous studies.

All of the 3 toxicants studied impaired juvenile survival and reproductive success of Tisbe battagliai individuals at aqueous concentrations well below solubility levels; hence, indicating potential environmental hazards to marine meiobenthic communities. Never- 
theless, hydrophobic pollutants such as PAH and pyrethroids tend to accumulate in sediment and food particles, and therefore disappear very rapidly from the water column (Zhou et al. 1995, Zhou \& Rowland 1997). Indeed, this questionable argument is often forwarded to support the use of such substances in aquaculture. Thus, meiobenthic copepods and probably most coastal organisms are likely to encounter hydrophobic pollutants in the sediment or bound to food sources (i.e. algae) (Chandler et al. 1994, Lotufo 1998). Several studies have reported that sensitivities of meiobenthic copepods to sediment-associated fluoranthene and pyrethroid insecticides were several orders of magnitude lower than those observed for other crustacea in water only exposures (Chandler 1990, Strawbridge et al. 1992, Chandler et al. 1994, Lotufo 1998). In the present study, T. battagliai females and egg survivorship were unaffected by algae spiked with near aqueous saturation levels of fluoranthene, cypermethrin and deltamethrin, (i.e. 60, 1.3 and $0.35 \mathrm{\mu g} \mathrm{l}^{-1}$, respectively). Conversely, naupliar production and hence reproductive success was dramatically reduced under exposure to contaminated algae with pyrethroid insecticides. Leppanen \& Kukkonen (2000) reported that low or no toxic effects of sediment-associated pyrethroids and PAH is related to the ability of extreme hydrophobic chemicals to strongly bind to sediment and algal particles. As a consequence, pyrethroids and PAHs bound to particles are less bioavailable to aquatic organisms. Hence, sensitive life-stages such as juveniles are more likely to be affected by sediment- or algae-associated hydrophobic chemicals than adults, and current views supporting the non-bioavailability of such substances would seem to be highly open to question.

Our results and those obtained in other studies (Chandler et al. 1994, Lotufo 1997, 1998) have shown that toxicity of fluoranthene and pyrethoid insecticides to meiobenthic copepods varied among aqueous, sediment and algae exposure routes. This means that the assessment of ecological effects of toxic chemicals in the coastal marine environment, monitoring programmes should include the 3 exposure routes: seawater, sediment and food. Here, we have shown that it is feasible to study toxic effects of food and aqueousassociated toxicants using a single test design with the meiobenthic copepod Tisbe battagliai. As an opportunistic epibenthonic scavenger, T. battagliai can also be exposed to pollutants associated with sediment (Lopez 1982, Villano \& Warwick 1995). This could be simply achieved from existing stage-specific or partial life-cycle sediment tests conducted with meiobenthic copepods (Chandler 1990, Lotufo 1998, Chandler \& Green 2001), for example limiting exposure periods of adults to 1 or 2 broods.

\section{CONCLUSIONS}

Although limited to only $6 \mathrm{~d}$, the results reported here indicate that for all 3 studied chemicals, a short exposure period was sufficient to adequately define the functional relationship between concentration and fitness-related life-history traits such as reproductive output and adult and juvenile mortality. It is also important to point out that no single test can yield a complete picture of the overall toxic response, as toxic effluents, contaminated sediments or even single chemicals may have multiple ecotoxicological modes of action. Thus ecotoxicological studies should focus on developing tests with greater flexibility in order to discover the interactions among these various ecotoxicological modes. Here, we have shown that by limiting the exposure period to sensitive age classes (i.e. reproductive females, nauplii) and measuring additional variables (egg survival, feeding rates), it is possible to develop a test design with a shorter duration than existing life-cycle bioassays. Nevertheless, to assess whether it is necessary to use exposure periods longer than 4 to $6 \mathrm{~d}$, short-term sensitivities to toxic chemicals should be compared with those obtained in life-table experiments (Bechmann 1994).

Acknowledgements. C.B. was supported by a Portuguese FCT grant PRAXIS XXI/BPD/1692/98 while carrying out this research. The authors gratefully acknowledge 4 anonymous reviews for useful comments on earlier versions of the manuscript.

\section{LITERATURE CITED}

Abel PD, Axiak V (1991) Ecotoxicology and the marine environment. Ellis Horwood, Chichester

Allen Y, Calow P, Baird DJ (1995) A mechanistic model of contaminant-induced feeding inhibition in Daphnia magna. Environ Toxicol Chem 14:1625-1630

ASTM (American Society of Testing Materials) (1988) Standard guide for conducting acute toxicity tests with fishes, macroinvertebrates, and amphibians. E 729-88. In: Annual Book of ASTM Standards, Philadelphia, PA, p 336-352

ASTM (American Society of Testing Materials) (1990) Standard guide for conducting life-cycle toxicity tests with saltwater mysids. E1191-90. In: Annual Book of ASTM Standards, Philadelphia, PA, p 754-769

Baird DJ, Barber I, Soares AMVM, Calow P (1991) An early life-stage test with Daphnia magna Straus: an alternative to the 21-day chronic test? Ecotoxicol Environ Saf 22:1-7

Barata C, Baird DJ (2000) Determining the ecotoxicological mode of action of toxicants from measurements on individuals: results from short duration chronic tests with Daphnia magna Straus. Aquat Toxicol 48:195-209

Barata C, Baird, DJ, Miñarro A, Soares AMVM (2000) Do genotype responses always converge from lethal to nonlethal toxicant exposure levels? A hypothesis tested using laboratory Daphnia magna Straus clones. Environ Toxicol Chem 19:2314-2322

Bechmann RK (1994) Use of life tables and $\mathrm{LC}_{50}$ tests to eval- 
uate chronic and acute toxicity effects of copper on the marine copepod Tisbe furcata (Baird). Environ Toxicol Chem 13:1509-1517

Bechmann RK (1999) Effect of the endocrine disrupter nonylphenol on the marine copepod Tisbe battagliai. Sci Total Environ 233:33-46

Boese BL, Lamberson JO, Swartz RC, Ozretich RJ (1997) Photoinduced toxicity of fluoranthene to seven marine benthic crustaceans. Arch Environ Contam Toxicol 32:389-393

Burridge LE, Haya K, Page FH, Waddy SL, Zitko V, Wade J (2000) The lethality of the cypermethrin formulation Excis to larval and post-larval stages of the American lobster (Homarus americanus). Aquaculture 182:37-47

Calow P, Sibly RM, Forbes V (1997) Risk assessment on the basis of simplified life-history scenarios. Environ Toxicol Chem 16:1983-1989

Carvalho F, Guilhermino L, Ribeiro R, Gonzalez F, Soares AMVM (1995) METIER (Modular Ecotoxicity Tests Incorporating Ecological Relevance). II. Ecotoxicology of poorly-water soluble compounds: concentration versus dose. Arch Environ Contam Toxicol 29:431-435

Chandler GT (1990) Effects of sediment-bound residues of the pyrethroid insecticide fenvalerate on survival and reproduction of meiobenthic copepods. Mar Environ Res 29: 65-76

Chandler GT, Green AS (2001) Developmental stage-specific life-cycle bioassay for assessment of sediment-associated toxicant effects on benthic copepod production. Environ Toxicol Chem 20:171-178

Chandler GT, Coull BC, Davis JC (1994) Sediment- and aqueous-phase fenvalerate effects on miobenthos: implications for sediment quality criteria development. Mar Environ Res 37:313-327

Clark JR, Goodman LR, Borthwick PW, Patrick JM, Cripe GM, Moody PM, Moore JC, Lores EM (1989) Toxicity of pyrethroids to marine invertebrates and fish: a literature review and test results with sediment-sorbed chemicals. Environ Toxicol Chem 8:391-401

Cripe GM (1994) Comparative acute toxicities of several pesticides and metals to Mysidopsis bahia and postlarval Penaeus duorarum. Environ Toxicol Chem 13:1867-1872

Day KE (1989) Acute, chronic and sublethal effects of synthetic pyrethroids on freshwater zooplankton. Environ Toxicol Chem 8:411-416

Day KE, Kaushik NK (1987) An assessment of the chronic toxicity of the synthetic pyrethroid fenvalerate, to Daphnia galeata mendotae, using life table. Environ Pollut Ser A Ecol Biol 12:70-84

Di Pinto LM, Coull BC, Chandler GT (1993) Lethal and sublethal effects of the sediment-associated PCB Aroclor 1254 on a meiobenthic copepod. Environ Toxicol Chem 12: 1909-1918

Forbes VE, Calow P (1999) Is the per capita rate of increase a good measure of population-level effects in ecotoxicology? Environ Toxicol Chem 18:1544-1556

Forbes VE, Calow P, Sibly RM (2001) Are current species extrapolation models a good basis for ecological risk assessment. Environ Toxicol Chem 20:442-447

Green AS, Chandler GT (1996) Life-table evaluation of sediment-associated chlorpyrifos chronic toxicity to the benthic copepod, Amphiascus tenuiremis. Arch Environ Contam Toxicol 31:77-83

Hayes W, Laws E (1991) Handbook of pesticide toxicology. Academic Press, London

Hutchinson TH, Williams TD (1989) The use of sheepshead minnow (Cypronodon variegatus) and a benthic copepod (Tisbe battagliai) in short-term tests for estimating the chronic toxicity of industrial effluents. Hydrobiologia 188/189:567-572

Hutchinson TH, Williams TD, Eales GJ (1994) Toxicity of cadmium, hexavalent chromium and copper to marine fish larvae (Cyprinodon varigatus) and copepods (Tisbe battagliai). Mar Environ Res 38:275-290

Hutchinson TH, Pounds NA, Hampel M, Williams TD (1999) Life-cycle studies with marine copepods (Tisbe battagliai) exposed to 20-hydroxyecdisone and diethylstilbestrol. Environ Toxicol Chem 18:2914-2920

Jak RG, Maas JL, Scholten MCT (1996) Evaluation of laboratory derived toxic effect concentrations of a mixture of metals by testing freshwater plankton communities in enclosures. Water Res 30:1215-1227

Kenish MJ (1992) Ecology of estuaries: anthropogenic effects. CRC Press, Boca Raton

Kleppel G, Burkart G (1995) Egg production and the nutritional environment of Acartia tonsa: the role of food quality and copepod production. ICES. J Mar Sci 5:297-304

Leppanen MT, Kukkonen JVK (2000) Effect of sedimentchemical contact time on availability of sediment-associated pyrene and benzo[a]pyrene to oligochaete worms and semi-permeable membrane devices. Aquat Toxicol 49:227-241

Lopez GW (1982) Short-term population dynamics of Tisbe cucumariae (Copepoda: Harpacticoida). Mar Biol 68:333-341

Lotufo GR (1997) Toxicity of sediment-associated PAHs to an estuarine copepod: effects on survival, feeding, reproduction and behaviour. Mar Environ Res 44:149-166

Lotufo GR (1998) Lethal and sublethal toxicity of sedimentassociated fluoranthene to benthic copepods: application of the critical-body-residue approach. Aquat Toxicol 44: $17-30$

Lotufo GR, Fleeger JW (1997) Effects of sediment-associated phenenthrene on survival, development and reproduction of two species of meiobenthic copepods. Mar Ecol Prog Ser 151:91-102

Martinez Galera M, Martinez Vidal JL, Garrido Frenich A, Gil Garcia DL (1996) Determination of cypermethrin, fenvalerate and cis and trans permethrin in soil and groundwater by high-performance-liquid-chromatography using partial least square regression. J Chromatogr A 727:39-46

Medina M, Barata C, Telfer T, Baird DJ (2002) Age- and sex related variation in sensitivity to the pyrethroid cypermethrin in the marine copepod Acartia tonsa Dana. Arch Environ Contam Toxicol 42:17-22

Moore M, Folk C (1993) Zooplankton body size and community structure-effects of thermal and toxicant stress. Trends Ecol Evol 8:178-183

Nogueira JAN (1996) Modelling the physiological performance of Daphnia (Crustacea:Cladocera) under stress. $\mathrm{PhD}$ thesis, University of Stirling

Roth M (2000) The availability and use of chemotherapeutic sea lice control products. Contrib Zool 69:109-118

Stearns SC (1992) The evolution of life histories. Oxford University Press, Oxford

Strawbridge S, Coull BC, Chandler GT (1992) Reproductive output of a meiobenthic copepod exposed to sediment associated fenvalerate. Arch Environ Contam Toxicol 23: 295-300

Thomas KV, Benstead RE, Thain JE, Waldock MJ (1999) Toxicity characterisation of organic contaminants in industrialised UK estuaries and coastal waters. Mar Pollut Bull 38: 925-932

Verschueren K (1983) Handbook of environmental data on organic chemicals, 2nd edn. Van Nostrand Reinhold Company, Berkshire 
Villano N, Warwick RM (1995) Meiobenthic communities associated with the seasonal cycle of growth and decay of Ulva rigida Agardh in the Palude Della Rosa, Lagoon of Venice. Estuar Coast Shelf Sci 41:181-194

Williams TD (1992) Survival and development of copepod larvae Tisbe battagliai in surface microlayer, water and sediment elutriates from German Bight. Mar Ecol Prog Ser 91:221-228

Williams TD, Jones MB (1994) Effects of temperature and food quality on postembryonic development of Tisbe battagliai (Copepoda: harpacticoida). J Exp Mar Biol Ecol

Editorial responsibility: Otto Kinne (Editor), Oldendorf/Luhe, Germany
183:283-298

Williams TD, Jones MB (1999) Effects of temperature and food quality on the reproduction of Tisbe battagliai (Copepoda: harpacticoida). J Exp Mar Biol Ecol 236:273-290

Zar JH (1996) Biostatistical analysis. Prentice-Hall, New York

Zhou JL, Rowland SJ (1997) Evaluation of the interactions between hydrophobic organic pollutants and suspended particles in estuarine waters. Water Res 31:1708-1718

Zhou JL, Rowland SJ, Mantoura RFC (1995) Partition of synthetic pyrethroid insecticides between dissolved and particulate phase. Water Res 29:1023-1031

Submitted: June 25, 2001; Accepted: October 2, 2001

Proofs received from author(s): March 14, 2002 